\title{
Genetic diversity of the tet(M) gene in tetracycline-resistant oral streptococci
}

\author{
Dasul Jeong ${ }^{1}$ and Si Young Lee ${ }^{2 \star}$ \\ ${ }^{1}$ Undergraduate Student, College of Dentistry, Gangneung-Wonju National University, Gangneung, Republic of Korea \\ ${ }^{2}$ Professor, Department of Microbiology and Immunology, College of Dentistry, Research Institute of Oral Science, Gangneung-Wonju National University, \\ Gangneung, Republic of Korea
}

Tetracycline resistance occurs at a high frequency among clinical isolates of both gram-positive and gram-negative bacteria. The mechanism and genetics of tetracycline resistance have not been extensively studied in streptococci, although the overwhelming majority of clinical isolates are tetracycline resistant. tet( $\mathrm{M})$ is the most common tetracycline-resistance gene in streptococci. The aim of this study was to examine the genetic diversity of tet( $\mathrm{M})$ genes in tetracycline-resistant oral streptococci from dental plaque. Streptococci were isolated from supragingival plaque samples of healthy persons. The isolates were then identified at the species level, and the minimum inhibitory concentration (MIC) of tetracycline was determined. Genomic DNA was extracted from tetracyclineresistant isolates and tet $(\mathrm{M})$ was amplified using polymerase chain reaction with tet( $\mathrm{M})$-specific primers. The polymerase chain reaction products were cloned, DNA sequencing was performed, and the sequences were compared using an alignment program. The estimated nucleotide divergence between different tet $(\mathrm{M})$ alleles ranged from $0.00 \%$ to $6.07 \%$ among oral streptococci. The tet $(\mathrm{M})$ genes from oral streptococci consisted of regions similar in sequence, interspersed with regions that differed at some nucleotide sites, revealing a mosaic structure. The percent nucleotide divergence of tet $(\mathrm{M})$ was unrelated to the MIC values of tetracycline for oral streptococci, and bacterial strains in the same streptococcal species showed different heterogeneity in tet $(\mathrm{M})$. The divergences of tet $(\mathrm{M})$ nucleotide sequences among oral streptococci were comparable with those of other bacterial genera. Our findings may provide basic information about the transposition processes associated with tet $(\mathrm{M})$ in oral streptococci.

Key Words: Diversity; Resistance; Sequence; Streptococci; Tetracycline

(c) This is an open-access article distributed under the terms of the Creative Commons Attribution Non-Commercial License (http://creativecommons.org/licenses/by-nc/4.0) which permits unrestricted noncommercial use, distribution, and reproduction in any medium, provided the original work is properly cited.

\section{Introduction}

Tetracyclines are broad-spectrum antibiotics that exhibit activity against a wide range of bacteria [1]. They are a family of antibiotics that inhibit protein synthesis by preventing the attachment of aminoacyl-tRNA to the ribosomal acceptor site. Tetracyclines also have a number of non-antibacterial effects, such as inhibition of collagenase, which was found to be therapeutically useful in periodontitis [2]. However, the extensive use of these agents has led to the emergence of antibiotic resistance.

Resistance to tetracycline occurs at high frequency among clinical isolates of both gram-positive and gramnegative bacteria [3]. The first tetracycline-resistant bacterium was isolated in 1953 [4]. Tetracycline-resistance genes mediate resistance mainly by two different mechanisms:

Received March 2, 2021; Revised April 9, 2021; Accepted April 24, 2021

*Corresponding author: Si Young Lee, Department of Microbiology and Immunology, College of Dentistry, Research Institute of Oral Science, Gangneung-Wonju National University, 7 Jukheon-gil, Gangneung 25457, Republic of Korea.

Tel: +82-33-640-2455, Fax: +82-33-642-6410, E-mail: siyoung@gwnu.ac.kr 
active efflux or ribosomal protection. The tetracycline-resistance genes tet $(\mathrm{K})$ or tet $(\mathrm{L})$ confer tetracycline resistance due to active efflux, which exports tetracycline from the cell, while the tet $(\mathrm{M})$, tet $(\mathrm{O})$, tet $(\mathrm{S})$, or tet $(\mathrm{W})$ genes express proteins that protect ribosomes from the action of tetracycline $[1,5]$.

The tet(M) gene is widely distributed among both grampositive and gram-negative bacteria and has been found in 59 genera [5]. Over the past two decades, many oral bacterial strains have been reported to be tetracycline resistant [6]. tet(M) is the most tetracycline-resistance gene in streptococci [1,4]. Particularly in gram-positive streptococci and enterococci, tet(M) has been associated with Tn916/Tn1545-like conjugative transposons that form the basis of a family of conjugative transposons having an extremely broad host range $[7,8]$. The mobile units of conjugative transposons have enabled the tet( $\mathrm{M})$ gene to move between species and into a wide range of genera by conjugative transposition [1]. In previous studies, analysis of the nucleotide sequences of tet $(\mathrm{M})$ genes from a diverse range of bacteria revealed that tet( $\mathrm{M})$ has evolved by recombination following transformation of DNA from a different strain carrying a different tet(M) allele [9,10]. Recombination between evolutionarily divergent tet( $\mathrm{M})$ genes exhibiting nucleotide variations [11] and genetic diversities of tet(M) in Staphylococcus aureus [7] and Streptococcus pneumonia [9] have been reported.

Dental plaque is comprised of more than 700 species of bacteria, including bacteria related to periodontal diseases [12]. Because oral streptococci constitute the major bacterial species found in human dental plaque [13], tetracycline-resistance genes present in oral streptococci may be a source for transferring tetracycline resistance to other bacteria present in the oral cavity. Although many clinical oral streptococcal isolates are tetracycline resistant, the genetics of tetracycline-resistance genes have not been extensively studied in oral streptococci $[14,15]$. Here, we examined the genetic diversity of tet $(\mathrm{M})$ genes in tetracyclineresistant oral streptococci from dental plaque.

\section{Materials and Methods}

\section{Bacterial strains and media}

Streptococci were isolated from the supragingival plaque samples of healthy persons. All volunteers willing to donate their plaques for this study were informed about the procedure and gave written consent for inclusion in the study. This study was approved by the Institutional Review Board of Gangneung-Wonju National University Dental Hospital (IRB 2011-2). Isolates were identified to the species level using the Rapid ID 32 Strep system and a mini API reader (bioMerieux, Marcy-1'Etoile, France). Seven specific viridans-group streptococcal species (Streptococcus anginosus, Streptococcus gordonii, Streptococcus mitis, Streptococcus mutans, Streptococcus oralis, Streptococcus salivarius, and Streptococcus sanguinis) were identified.

\section{Susceptibility testing}

To determine the minimal inhibitory concentration (MIC) of the antibiotic, stock antibiotic solution of tetracycline (Sigma-Aldrich Chemical Co., St. Louis, MO, USA) was prepared. The MICs were determined according to Clinical and Laboratory Standards Institute (CLSI) guidelines using a microdilution method in cation-adjusted MuellerHinton broth supplemented with lysed horse blood. Using streptococcal colonies taken directly from sheep-blood agar plates (KOMED, Seongnam, Korea), which were incubated at $37^{\circ} \mathrm{C}$ for 18 hours in aerobic conditions, a suspension equivalent to that of the $0.5 \mathrm{McFarland}$ standard ( $1 \times$ $10^{8} \mathrm{CFU} / \mathrm{mL}$ ) in cation-adjusted Mueller-Hinton broth was prepared. The bacteria were inoculated into serially diluted antibiotic solutions in 96-well microtitration plates at final concentrations of $5 \times 10^{5} \mathrm{CFU} / \mathrm{mL}$. The microtitration plates were incubated in an ambient-air incubator at $37^{\circ} \mathrm{C}$ for 24 hours. The microtitration plates were read visually and the minimum concentration of the antibiotics that produced no turbidity was recorded as the MIC. Antibiotic resistance was determined by interpretive standard concentrations from CLSI guidelines [16] and tests were repeated at least twice. The range of concentrations tested for each antibiotic was from $0.001-1,024 \mu \mathrm{g} / \mathrm{mL}$. 


\section{Identification of tetracycline-resistance determinants by polymerase chain reaction (PCR)}

Genomic DNA was extracted from the tetracyclineresistant strains using an Accuprep Genomic DNA Extraction Kit (Bioneer, Daejeon, Korea) and stored at $-70^{\circ} \mathrm{C}$. PCR analysis was performed using Bioneer HotStart Taq polymerase (Bioneer). Gene primer sequences were as follows: tet(M) forward, 5' - AGT TTT AGC TCA TGT TGA TG-3'; tet(M) reverse, 5' -TCC GAC TAT TTG GAC GAC GG-3' [9]. PCR amplification was performed in a DNA Thermal Cycler (GeneAMP PCR System 9700; Perkin Elmer, Waltham, MA, USA) under the following conditions: an initial incubation at $95^{\circ} \mathrm{C}$ for 5 minutes, 35 cycles of $95^{\circ} \mathrm{C}$ for 1 minute, $50^{\circ} \mathrm{C}$ for 1 minute, and $72^{\circ} \mathrm{C}$ for 30 seconds, followed by a final incubation at $72^{\circ} \mathrm{C}$ for 5 minutes. PCR products were electrophoretically separated on a $1 \%$ agarose gel, stained with ethidium bromide, and visualized by ultraviolet transilluminator. The size of the tet(M) gene following DNA amplification was 1,862 bp.

Table 1. Minimal inhibitory concentration (MIC) of tetracycline

\begin{tabular}{lc}
\hline \multicolumn{1}{c}{ Strains } & Tetracycline MIC $(\mu \mathrm{g} / \mathrm{mL})$ \\
\hline Streptococcus anginosus KN154 & 64 \\
S. anginosus KN157 & 128 \\
Streptococcus gordonii KN164 & 16 \\
S. gordonii KN469 & 64 \\
Streptococcus mitis KN82 & 64 \\
S. mitis KN172 & 64 \\
Streptococcus mutans KN533 & 16 \\
Streptococcus oralis KN64 & 128 \\
S. oralis KN152 & 4 \\
Streptococcus salivarius KN460 & 128 \\
Streptococcus sanguinis KN16 & 32 \\
S. sanguinis KN158 & 32 \\
\hline
\end{tabular}

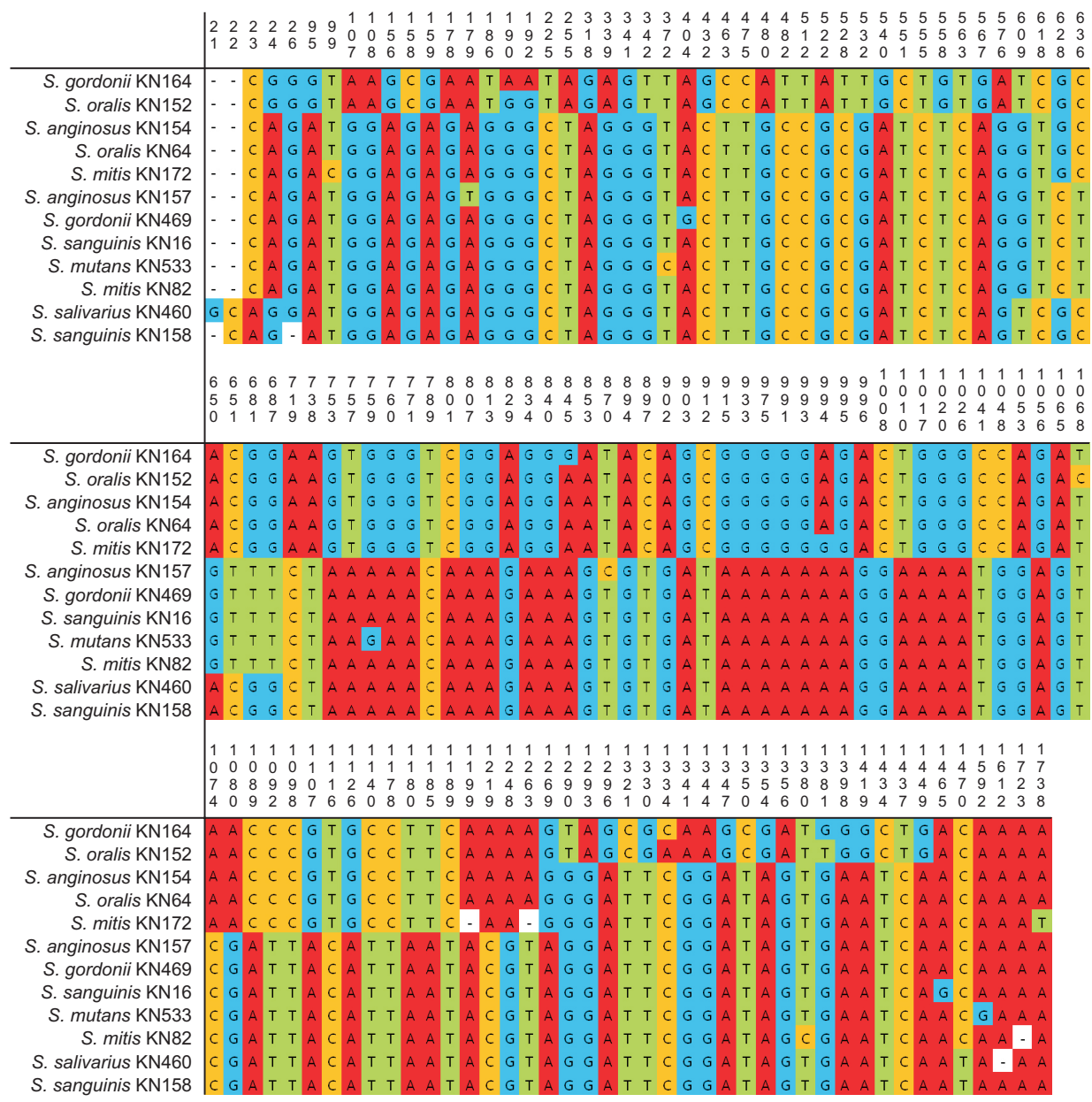

Fig. 1. Illustration of tet(M) diversity highlighting only the polymorphic sites in both nucleotide sequence alignments. Numbering begins at the first residue of the forward primer site. 


\section{Cloning and sequence analysis}

Among the strains containing tet(M), 12 were selected for further analysis of tet(M) genetic diversity. We included at least one strain from each of the seven streptococcal species and all the strains were randomly selected from within the same species. The PCR products were purified using an Accuprep Gel Purification Kit (Bioneer) and subsequently cloned into a PCR 4-TOPO vector from a TOPO TA Cloning Kit (Invitrogen, Carlsbad, CA, USA) according to manufacturer instructions. The cloned tet(M) PCR products were transformed into One Shot TOP 10 Escherichia coli $\mathrm{DH} 5 \alpha-\mathrm{T} 1^{\mathrm{R}}$ competent cells, and the plasmids were harvested from cultured E. coli with an Accuprep Nano-Plus Plasmid Mini Extraction Kit (Bioneer). DNA sequencing was performed by Macrogen (Seoul, Korea) using the following primers: T3, 5'-ATT AAC CCT CAC TAA AGG GA-3'; T7, 5' -TAA TAC GAC TCA CTA TAG GG-3'; OM139, 5' -TCG AGG TCC GTC TGA AC-3' [7], OM140, 5'-AAC AGA AGG TAG AAC TG T-3'. The OM139 and OM140 primers were designed with the GenScript DNA sequencing primerdesign tool (http://www.genscript.com/cgi-bin/tools/ sequencing_primer_design). The DNA sequences were compared using an alignment program [17].

\section{Results}

Tetracycline-susceptibility tests were performed for 635 streptococcal isolates, with 148 isolates being determined to be tetracycline resistant. Among the 148 tetracycline-resistant oral streptococcal strains, 68 (46\%) contained tet(M). Twelve strains from the 68 tet(M)-positive isolates were selected for tet(M) sequence analysis. The MICs of these isolates for tetracycline are presented in Table 1.

Comparison of only polymorphic sites among the sequences is shown in Fig. 1. It was revealed that genetic variation in tet(M) is not randomly distributed. The mosaic distribution of polymorphic sites suggested that localized recombination events may have occurred. The results of sequence analysis are shown in Table 2 . The number of different nucleotides between different tet(M) alleles varied from 0 to 113 , corresponding to the estimated nucleotide divergence ranging from 0\% ( $S$. anginosus KN154 and $S$.

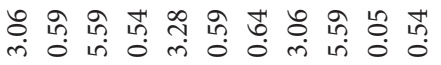

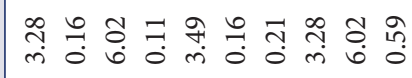

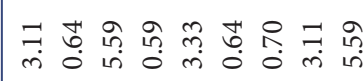

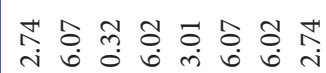

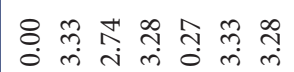

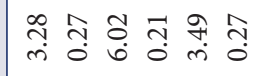

m

तิ

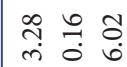

$\stackrel{4}{\stackrel{4}{*}}$

$\stackrel{m}{m}$

m.

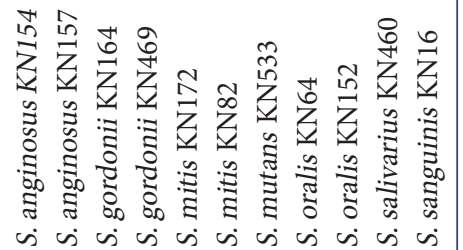


Table 3. The comparison of nucleotide sequences between Streptococcus gordonii KN164 and tet(M) from bacteria reported in the National Center for Biotechnology Information database

\begin{tabular}{lccc}
\hline \multicolumn{1}{c}{ Bacterial species } & Number of different nucleotides & Difference (\%) & Reference \\
\hline Clostridium septicum & 5 & 0.27 & Sasaki et al. [21] \\
Enterococcus faecalis & 110 & 5.91 & Perreten et al. [22] \\
Escherichia coli & 105 & 5.64 & Jones et al. [23] \\
Lactococcus lactis & 110 & 5.91 & Florez et al. [24] \\
Lactobacillus sakei & 151 & 8.11 & Ammor et al. [25] \\
Staphylococcus aureus & 153 & 8.22 & Nesin et al. [26] \\
Streptococcus oralis & 6 & 0.32 & Ciric et al. [27] \\
Streptococcus pneumoniae & 71 & 3.81 & Del Grosso et al. [28] \\
Streptococcus pneumoniae & 43 & 2.31 & Provvedi et al. [29] \\
Streptococcus suis & 89 & 4.78 & Ye et al. [30] \\
\hline
\end{tabular}

oralis KN64) to $6.07 \%$ (S. gordonii KN164 and S. anginosus KN157; S. gordonii KN164 and S. mitis KN82; S. oralis KN152 and S. anginosus KN157; S. oralis KN152 and S. mitis KN82). Genetic consistencies were not found within the same species.

To examine the sequence divergence of tet $(\mathrm{M})$ from oral streptococci used in this study with other bacterial species, we compared the nucleotide sequence of $S$. gordonii KN164, which showed the most divergent tet(M) sequence among the oral streptococcal strains used in this study, with the tet(M) sequences of other bacteria from the National Center for Biotechnology Information database. The divergence data is shown in Table 3. The sequence differences ranged from $0.27 \%$ with Clostridium septicum to $8.22 \%$ with $S$. aureus.

\section{Discussion}

Several studies reported the prevalence of tetracycline resistance in oral streptococci, with the severity of the prevalence varying among studies conducted in different countries. In London, Stapleton et al. [11] found tet(M) in 14 out of 22 strains (63.6\%), while a study conducted in Spain by Rodriguez-Avial et al. [18] reported that 35\% of oral streptococcal strains were resistant to tetracycline, and that among these, $77.8 \%$ contained tet(M). In Belgium, 114 out of 157 strains $(72.6 \%)$ exhibited tetracycline resistance and among these, 105 (92.1\%) were tet(M) positive [19].

The tet(M) determinant is mostly non-plasmid associated and mediates resistance to minocycline, as well as tetracy- cline [3]. One of the reasons for the success of this gene is that it is commonly contained within conjugative transposons, which have an extraordinarily broad host range $[1,8]$. According to de Vries et al. [7], conjugative transposition plays an important role in the evolution and horizontal spread of tet(M) in $S$. aureus, with $S$. aureus of human origin containing diverse tet(M) variants located on Tn916- and Tn5801-like (Tn6014) transposons.

Previous studies demonstrated the heterogeneity of the tet(M) genes. Rizzotti et al. [20] reported divergence of the enterococcus tet(M) gene in up to $10.9 \%$ of the tet(M) sequence. Doherty et al. [9] examined the stability and evolution of tet(M)-mediated resistance to tetracycline among members of different clonal lineages of $S$. pneumonia and reported that the estimated nucleotide divergence between different tet $(\mathrm{M})$ alleles ranged from $0.44 \%$ to $8 \%$.

In our data, the tet(M) genes of oral streptococci consisted of regions similar in sequence and interspersed with regions that differed at nucleotide sites, revealing a mosaic structure. The mosaic structure of tet(M) genes has also been observed in other bacterial species. Oggioni et al. [10] analyzed the nucleotide sequences of tet $(\mathrm{M})$ genes from a diverse range of bacteria. They compared the sequences of eight different tet(M) genes and detected a mosaic structure that could be traced to two distinct alleles. It appeared that the mosaic structure within tet( $\mathrm{M})$ had evolved after acquisition of the gene by mobile genetic elements. The block structure of these genes provides evidence for the contribution of homologous recombination to the evolution and the heterogeneity of the tet(M) locus. The effect of these 
mosaic structures on tetracycline resistance has not been formally addressed. It is known that streptococci carrying different tet(M) gene subtypes can confer different levels of tetracycline resistance [9]; however, this phenomenon was not observed in the oral streptococci used in our study.

Streptococci make up a large contingent of oral bacteria. It is assumed that they are potential sources of tetracyclineresistance genes for other bacteria, including the bacteria that cause periodontal disease. When the transposon containing a tetracycline-resistance gene moves between the chromosomes of bacteria in the oral cavity, transfer of tetracycline resistance may occur. However, further studies are necessary to reveal the possibility of transferring genes associated with tetracycline resistance between oral bacterial species.

The data presented in our study provide basic information about the transposition process associated with tet(M) in oral streptococci. The mosaic distribution of polymorphic sites suggests that highly localized recombination events may have occurred during the transposition process. However, further studies on larger samples of accumulated data over time are required to clarify the transfer mechanism associated with this gene. This will aid the acquisition of a more detailed understanding of the diversity of the tet(M) gene and the course of its spread.

\section{Conflicts of Interest}

The authors declare that they have no competing interests.

\section{ORCID}

\author{
Dasul Jeong \\ https://orcid.org/0000-0002-4815-7213 \\ Si Young Lee \\ https://orcid.org/0000-0001-8826-1413
}

\section{References}

1. Chopra I, Roberts M. Tetracycline antibiotics: mode of action, applications, molecular biology, and epidemiology of bacterial resistance. Microbiol Mol Biol Rev 2001;65:232260. doi: 10.1128/MMBR.65.2.232-260.2001.
2. Golub LM, Lee HM, Ryan ME, Giannobile WV, Payne J, Sorsa T. Tetracyclines inhibit connective tissue breakdown by multiple non-antimicrobial mechanisms. Adv Dent Res 1998;12:12-26. doi: 10.1177/08959374980120010501.

3. Burdett V, Inamine J, Rajagopalan S. Heterogeneity of tetracycline resistance determinants in Streptococcus. J Bacteriol 1982;149:995-1004. doi: 10.1128/JB.149.3.9951004.1982.

4. Roberts MC. Tetracycline resistance determinants: mechanisms of action, regulation of expression, genetic mobility, and distribution. FEMS Microbiol Rev 1996;19:1-24. doi: 10.1111/j.1574-6976.1996.tb00251.x.

5. Roberts MC. Update on acquired tetracycline resistance genes. FEMS Microbiol Lett 2005;245:195-203. doi: 10.1016/j.femsle.2005.02.034.

6. Walker $\mathrm{CB}$. The acquisition of antibiotic resistance in the periodontal microflora. Periodontol 2000 1996;10:79-88. doi: 10.1111/j.1600-0757.1996.tb00069.x.

7. de Vries LE, Christensen H, Skov RL, Aarestrup FM, Agers $\varnothing$ Y. Diversity of the tetracycline resistance gene tet(M) and identification of Tn916- and Tn5801-like (Tn6014) transposons in Staphylococcus aureus from humans and animals. J Antimicrob Chemother 2009;64:490-500. doi: 10.1093/jac/dkp214.

8. Rice LB. Tn916 family conjugative transposons and dissemination of antimicrobial resistance determinants. Antimicrob Agents Chemother 1998;42:1871-1877. doi: 10.1128/ AAC.42.8.1871.

9. Doherty N, Trzcinski K, Pickerill P, Zawadzki P, Dowson CG. Genetic diversity of the tet(M) gene in tetracyclineresistant clonal lineages of Streptococcus pneumoniae. Antimicrob Agents Chemother 2000;44:2979-2984. doi: 10.1128/aac.44.11.2979-2984.2000.

10. Oggioni MR, Dowson CG, Smith JM, Provvedi R, Pozzi G. The tetracycline resistance gene tet(M) exhibits mosaic structure. Plasmid 1996;35:156-163. doi: 10.1006/ plas.1996.0018.

11. Stapleton P, Adams V, Pike R, Lucas V, Roberts G, Mullany P, Rowbury R, Wilson M, Richards H. Characterisation of viridans group streptococci with different levels of Tet(M)mediated tetracycline resistance. Int J Antimicrob Agents 2004;24:439-443. doi: 10.1016/j.ijantimicag.2004.06.003.

12. Minarovits J. Anaerobic bacterial communities associated with oral carcinoma: intratumoral, surface-biofilm and salivary microbiota. Anaerobe 2020 Nov 24 [Epub]. http:// doi.org/10.1016/j.anaerobe.2020.102300.

13. Coykendall AL. Classification and identification of the viridans streptococci. Clin Microbiol Rev 1989;2:315-328. doi: 10.1128/cmr.2.3.315.

14. Teng LJ, Hsueh PR, Chen YC, Ho SW, Luh KT. Antimicrobial susceptibility of viridans group streptococci in Taiwan with an emphasis on the high rates of resistance to penicillin and macrolides in Streptococcus oralis. J Antimicrob 
Chemother 1998;41:621-627. doi: 10.1093/jac/41.6.621.

15. Potgieter E, Carmichael M, Koornhof HJ, Chalkley LJ. In vitro antimicrobial susceptibility of viridans streptococci isolated from blood cultures. Eur J Clin Microbiol Infect Dis 1992;11:543-546. doi: 10.1007/BF01960811.

16. Wikler MA; Clinical and Laboratory Standards Institute. Methods for dilution antimicrobial susceptibility tests for bacteria that grow aerobically. 8th ed. Wayne: Clinical and Laboratory Standards Institute; 2009.

17. Corpet F. Multiple sequence alignment with hierarchical clustering. Nucleic Acids Res 1988;16:10881-10890. doi: 10.1093/nar/16.22.10881.

18. Rodriguez-Avial I, Rodriguez-Avial C, Culebras E, Picazo JJ. Distribution of tetracycline resistance genes tet(M), tet $(\mathrm{O})$, tet $(\mathrm{L})$ and tet( $\mathrm{K})$ in blood isolates of viridans group streptococci harbouring erm(B) and mef(A) genes. Susceptibility to quinupristin/dalfopristin and linezolid. Int J Antimicrob Agents 2003;21:536-541. doi: 10.1016/s09248579(03)00062-1.

19. Malhotra-Kumar S, Lammens C, Martel A, Mallentjer C, Chapelle S, Verhoeven J, Wijdooghe M, Haesebrouck F, Goossens H. Oropharyngeal carriage of macrolideresistant viridans group streptococci: a prevalence study among healthy adults in Belgium. J Antimicrob Chemother 2004:53:271-276. doi: 10.1093/jac/dkh026.

20. Rizzotti L, La Gioia F, Dellaglio F, Torriani S. Molecular diversity and transferability of the tetracycline resistance gene tet(M), carried on Tn916-1545 family transposons, in enterococci from a total food chain. Antonie Van Leeuwenhoek 2009;96:43-52. doi: 10.1007/s10482-009-93347.

21. Sasaki Y, Yamamoto K, Tamura Y, Takahashi T. Tetracycline-resistance genes of Clostridium perfringens, Clostridium septicum and Clostridium sordellii isolated from cattle affected with malignant edema. Vet Microbiol 2001;83:6169. doi: 10.1016/s0378-1135(01)00402-3.

22. Perreten V, Kolloffel B, Teuber M. Conjugal transfer of the Tn916-like transposon TnFO1 from enterococcus faecalis isolated from cheese to other gram-positive bacteria. Syst Appl Microbiol 1997;20:27-38. doi: 10.1016/S07232020(97)80045-8.
23. Jones $\mathrm{CH}$, Tuckman M, Murphy E, Bradford PA. Identification and sequence of a tet( $\mathrm{M})$ tetracycline resistance determinant homologue in clinical isolates of Escherichia coli. J Bacteriol 2006;188:7151-7164. doi: 10.1128/JB.00705-06.

24. Flórez AB, Ammor MS, Mayo B. Identification of tet(M) in two Lactococcus lactis strains isolated from a Spanish traditional starter-free cheese made of raw milk and conjugative transfer of tetracycline resistance to lactococci and enterococci. Int J Food Microbiol 2008;121:189-194. doi: 10.1016/j.ijfoodmicro.2007.11.029.

25. Ammor MS, Gueimonde M, Danielsen M, Zagorec M, van Hoek AH, de Los Reyes-Gavilán CG, Mayo B, Margolles A. Two different tetracycline resistance mechanisms, plasmidcarried tet(L) and chromosomally located transposonassociated tet(M), coexist in Lactobacillus sakei Rits 9. Appl Environ Microbiol 2008;74:1394-1401. doi: 10.1128/ AEM.01463-07.

26. Nesin M, Svec P, Lupski JR, Godson GN, Kreiswirth B, Kornblum J, Projan SJ. Cloning and nucleotide sequence of a chromosomally encoded tetracycline resistance determinant, tetA(M), from a pathogenic, methicillin-resistant strain of Staphylococcus aureus. Antimicrob Agents Chemother 1990;34:2273-2276. doi: 10.1128/aac.34.11.2273.

27. Ciric L, Mullany P, Roberts AP. Antibiotic and antiseptic resistance genes are linked on a novel mobile genetic element: Tn6087. J Antimicrob Chemother 2011;66:22352239. doi: $10.1093 / \mathrm{jac} / \mathrm{dkr} 311$.

28. Del Grosso M, Scotto d'Abusco A, Iannelli F, Pozzi G, Pantosti A. Tn2009, a Tn916-like element containing mef(E) in Streptococcus pneumoniae. Antimicrob Agents Chemother 2004;48:2037-2042. doi: 10.1128/AAC.48.6.20372042.2004.

29. Provvedi R, Manganelli R, Pozzi G. Characterization of conjugative transposon Tn5251 of Streptococcus pneumoniae. FEMS Microbiol Lett 1996;135:231-236. doi: 10.1111/j.15746968.1996.tb07994.x.

30. Ye C, Bai X, Zhang J, Jing H, Zheng H, Du H, Cui Z, Zhang S, Jin D, Xu Y, Xiong Y, Zhao A, Luo X, Sun Q, Gottschalk M, Xu J. Spread of Streptococcus suis sequence type 7, China. Emerg Infect Dis 2008;14:787-791. doi: 10.3201/ eid1405.070437. 